\title{
Hydrothermal Liquefaction of Lignin
}

\author{
Julia Schuler¹, Ursel Hornung1, Andrea Kruse², Nicolaus Dahmen'1, Jörg Sauer1 \\ ${ }^{1}$ Karlsruhe Institute of Technology, Institute of Catalysis Research and Technology (IKFT), Karlsruhe, Germany \\ ${ }^{2}$ University of Hohenheim, Stuttgart, Germany \\ Email: Julia.schuler@kit.edu
}

How to cite this paper: Schuler, J., Hornung, U., Kruse, A., Dahmen, N. and Sauer, J. (2017) Hydrothermal Liquefaction of Lignin. Journal of Biomaterials and Nanobiotechnology, 8, 96-108.

http://dx.doi.org/10.4236/jbnb.2017.81007

Received: November 21, 2016

Accepted: January 17, 2017

Published: January 20, 2017

Copyright $\odot 2017$ by authors and Scientific Research Publishing Inc. This work is licensed under the Creative Commons Attribution International License (CC BY 4.0).

http://creativecommons.org/licenses/by/4.0/

(c) (7) Open Access

\begin{abstract}
The majority of platform chemicals are currently provided through crude oil processes. Nevertheless, the substitution of the crude oil with biomass should be the ecological aim. Lignin, an aromatic macromolecule, may play an important role in that exchange, as it is the only bio based source of aromatic compounds. For instance, it could be a source of bifunctional aromatic molecules, like the monocyclic compounds catechol or guaiacol, or bifunctional oligomers. However, no process for the production of aromatics from lignin in technical scale has been established until now. Hence, the focus of this work is to clarify the chemical degradation mechanism under hydrothermal conditions, to liquefy lignin delivering high functional molecules and to increase the yield and selectivity of the cleavage towards bifunctional molecules like catechol. The combination of fast hydrolysis, thermal degradation reactions and hydrogenation drives the hydrothermal liquefaction; this gives the possibility to narrow down the product spectrum in comparison to other "dry" cleavage methods, towards a higher yield of e.g. catechols.
\end{abstract}

\section{Keywords}

Lignin Liquefaction, Hydrothermal Cleavage, Chemical Use of Biomass

\section{Introduction}

Nowadays, platform chemicals are mostly provided through crude oil processes. The environmental influences accounted for by using crude oil are already visible. So, environmentally friendly alternates should be used now and in the future. Furthermore, alternatives should be investigated right now, when there is still time till crude oil sources dry out and as long as we can handle the situation. An environmental and carbon dioxide neutral carbon source for platform chemicals is wood based biomass. Wood based biomass contains mostly hemicellulose, cellulose and lignin. Lignin is one of the most common organic compounds in the world. It is the only bio based macro molecule which contains aromatic structures. Lignin is used in plants to build up solidifying structures and to resist environmental influences [1] [2]. On the one hand, this fact 
makes lignin a challenge for its conversion to produce chemicals and special treatments are necessary and need to be understood well.

On the other hand, lignin is a promising renewable resource available in large quantities, which could be used chemically. Currently, most of the directly useable lignin accrues at the paper industry as a byproduct in an amount of about fifty million tons per year. Most of this lignin is burned for energy production and hardly any of it is used as a raw material to produce chemicals like vanillin [3] [4]. Therefore, lignin provides a large potential source for the production of chemicals.

Bark is also a byproduct of huge amounts in the pulping industry and mostly not used. Hardwood bark, like beech bark, contains around 30\% of lignin [5]. Previous measurements also show a lignin content of about $32 \%^{1}$. For using lignin as a source for platform chemicals, different studies with the overall target to find a process which delivers platform chemicals out of every applied biomass that accrue as waste, like bark or Kraft lignin from pulping, need to be performed. Producing renewable energies always depends on environmental influences like weather. With such a process, there would not be any influences by the weather or anything in regard of the use of renewable sources for energy. However, the different behaviors of the biomass must be looked at to understand the reaction and to create a process like that. For the chemical use of lignin to gain platform chemicals, a depolymerization step is necessary. Therefore, the hydrothermal liquefaction is considered to be a promising system, because the hydrothermal cleavage is showing auspicious results. The chemical degradation mechanism under hydrothermal conditions to liquefy lignin delivering high functional molecules is investigated in this work. It is also the aim to increase the selectivity and yield of the cleavage towards bifunctional molecules, e.g. catechol. Catechol has a high potential as a platform chemical because of two present hydroxy groups and can be used as a precursor to fine chemicals such as perfumes and pharmaceuticals or as a building block in the organic synthesis.

\section{Hydrothermal Cleavage}

\subsection{Hydrothermal Treatment}

In the beginning of the research work on chemical lignin utilization, the main idea was to produce phenol out of the lignin. However, a process for the technical production of phenol is still not established until now, because the phenol yield stagnates at a certain point and so just the production of phenol is not profitable [6].

To understand that bottleneck, and to solve the problems of this special biomass, various reaction pathways have to be understood, before lignin can be used industrially.

Nevertheless, lignin could be a source for many monomeric and oligomeric compounds with more than one functional group. The idea of using lignin should therefore, be to generate more than one target molecule instead of just phenol as a product. The gained products depend on different depolymerization methods and used lignins [7].

By using hydrothermal liquefaction methods functional groups can be maintained, in contrast for example to the hydrotreating process [8]. Around $200^{\circ} \mathrm{C}$ and the corres-

${ }^{1}$ With M. Fleckenstein, University of Göttingen, Wood Biology \& Wood Products. 
ponding pressure of water, hydrothermal carbonization takes place, above $600^{\circ} \mathrm{C}$ supercritical water gasification. For the production of platform chemicals, a temperature ranging from $150^{\circ} \mathrm{C}$ to $400^{\circ} \mathrm{C}$ with the corresponding equilibrium pressures, delivers the best results. The desired hydrothermal liquefaction takes place between $280^{\circ} \mathrm{C}$ $380^{\circ} \mathrm{C}$ (Figure 1) [8].

In water, the selectivity towards keeping the functional groups is higher, as for example in ethanol [6]. Likewise, the biomass can be used without previous drying.

The special properties of water under these near and supercritical conditions offer special opportunities for gaining bifunctional aromatics (Figure 2). These special properties will be used in all the reaction to degrade lignin.

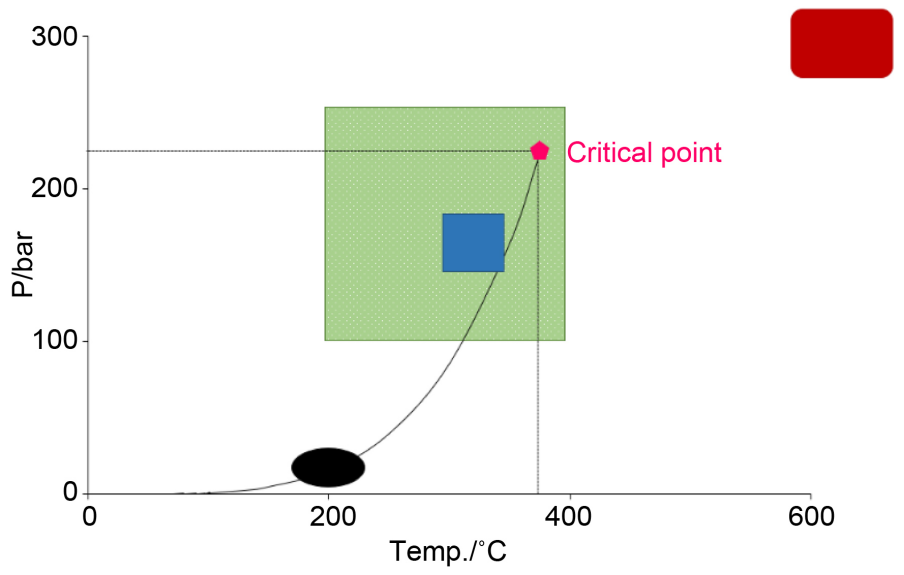

Figure 1. Hydrothermal treatment as a function of the pressure and temperature of water. Green area marks the conditions of the hydrothermal conversion to platform chemicals. The black circle marks the area of the hydrothermal carbonization, the dark red square the supercritical water gasification and the blue one the area of the hydrothermal liquefaction [8].

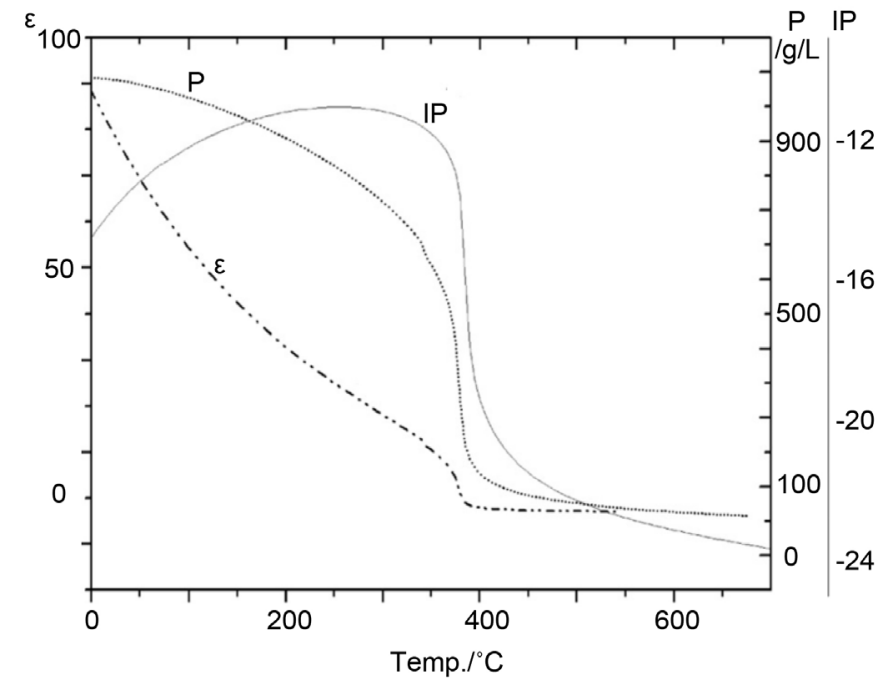

Figure 2. Properties of water as a function of temperature at the critical pressure $25 \mathrm{MPa}$ (density $\rho$, ion product IP and relative static dielectric constant $\varepsilon$ ) [8]. 
Under near or supercritical conditions water has a different density $\rho$, which leads to different solubilities for substances to be dissolved, different ion products IP, different relative static dielectric constant $\mathcal{E}$ and hydrogen availability through the occurring water gas shift reaction [8] [9].

\subsection{Lignin Structure}

In lignin, the macromolecule structure of aromatic rings is linked via different chemical groups and bond types (Figure 3 ) and besides this until now no detailed knowledge about the size of these structures could be acquainted [10]. Some forestry scientists even proposed that some trees might share the same molecule [11].

Lignin consists of three basic monomeric units of which the distribution depends on the type of plant which produced the lignin (Figure 4) [12]. So, every plant delivers different lignin and also the separation process has a big impact on the structure of the obtained lignin [7] [13].

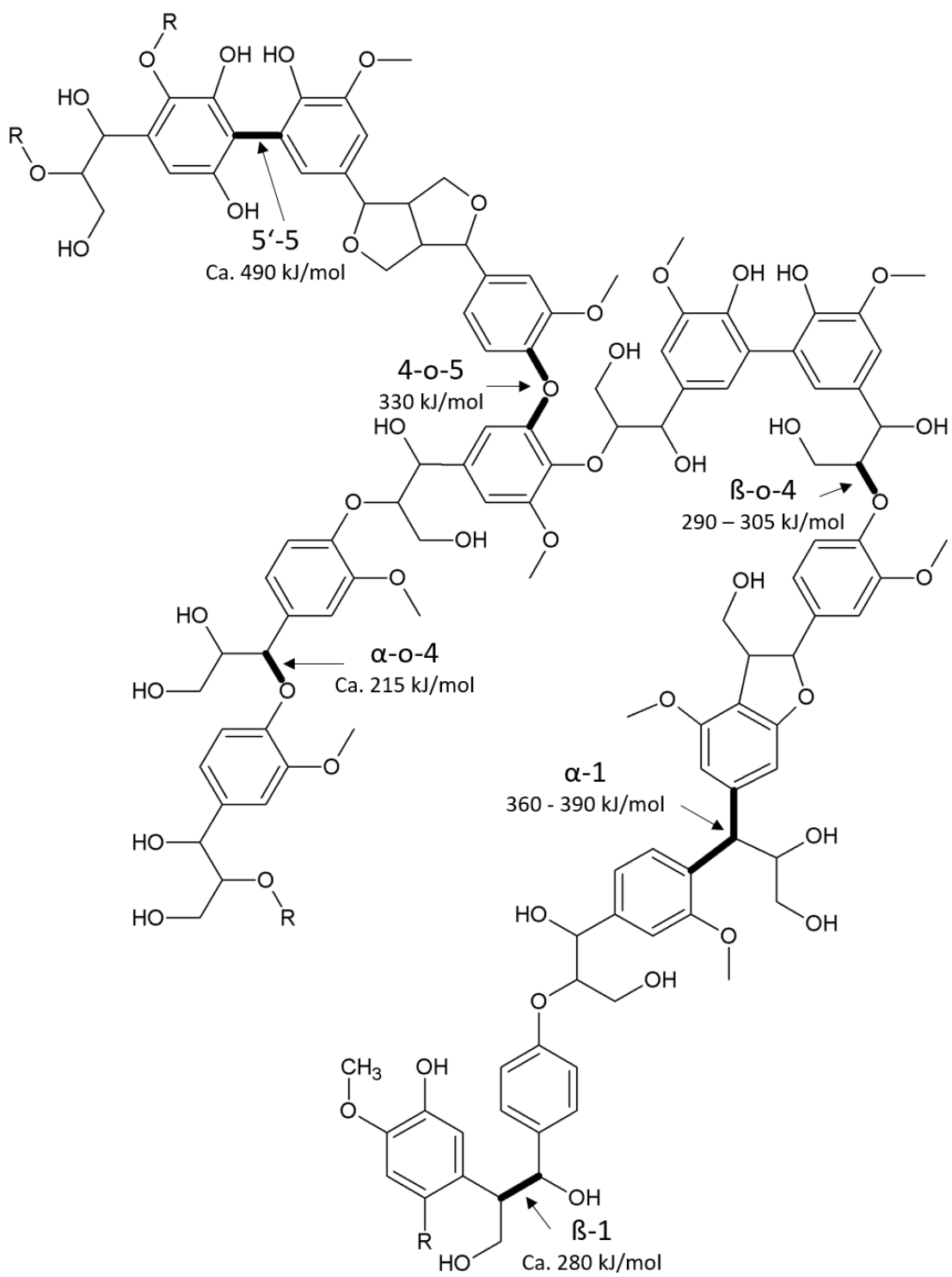

Figure 3. Possible structure of a lignin molecule with binding energies [10]. 
Sinapyl alcohol, p-cumaryl alcohol and coniferyl alcohol are the basic monomeric units of lignin. Sinapyl alcohol leads to syringol as a product, while coniferyl alcohol leads to guaiacol by hydrothermal treatment. The most common bond in the lignin molecule is the $\beta$-O- 4 , which has a relative low bond energy and is hence one of the first bonds which are cleaved during the liquefaction process (Figure 3) [12] [14].

The aromatic part of the lignin molecule is a precursor for phenolic monomers or oligomers. Methoxy groups lead to products like methane or methanol. Water soluble acids occur through alkene and alcohol side groups (Figure 5) [9] [13].

Liquefaction products with two functional groups, like catechols, are promising molecules for the use as a platform chemical (Figure 6). They can be used as a monomer for the production of polymers or precursors to fine chemicals.

\section{Experiments}

\subsection{Lignin-Indulin AT-Structure}

A Kraft lignin produced by the Kraft pulping process using sodium sulfide for lignin dissolution was applied in these studies. Indulin AT is a lignin which contains mostly $\beta$-O-4 linkages and basic units of coniferyl alcohol [12] [13].

The Indulin AT structure in this study contains mostly coniferyl alcohol, then pcumaryl alcohol and no sinapyl alcohol units (Table 1). So, based on the structure of this lignin type, the cleavage is presumed to deliver mostly guaiacol.

The units are linked mainly through $\beta$-O- 4 bonds (59\%), $\beta$ - $\beta$ bonds to $28 \%$ while the

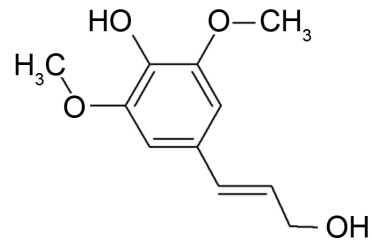

Sinapyl alcohol

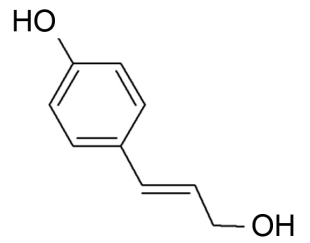

p-coumaryl alcohol

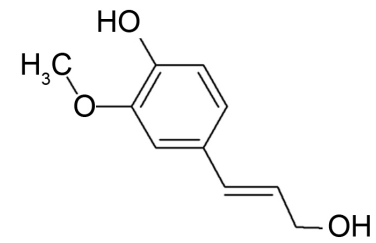

Coniferyl alcohol

Figure 4. Monomeric building blocks of lignin: Sinapyl alcohol, p-Cumaryl alcohol and Coniferyl alcohol.

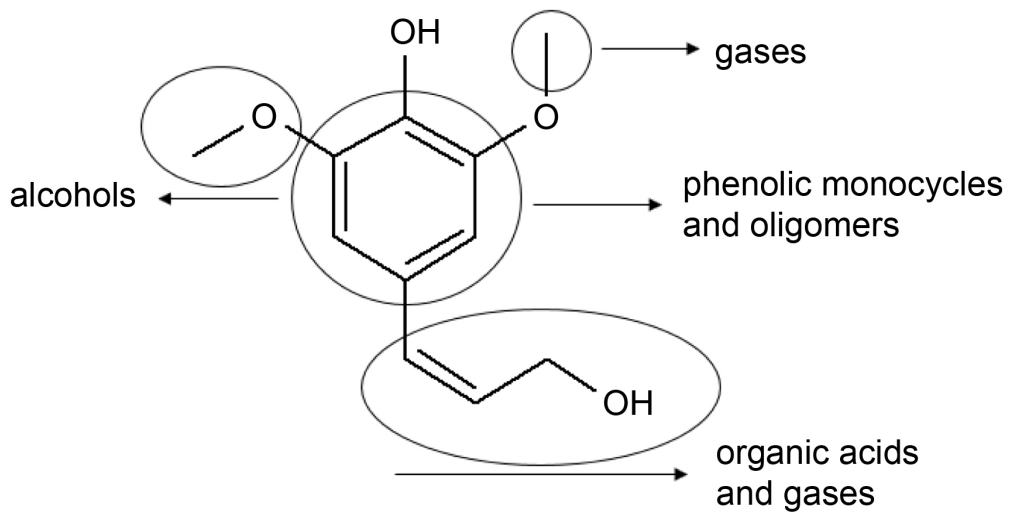

Figure 5. Simplified illustration of the precursors for thermal degradation products of a lignin monomer unit. 
<smiles>Oc1ccccc1</smiles>

Phenol<smiles>Oc1ccccc1O</smiles>

Catechol<smiles>COc1ccccc1O</smiles>

Guaiacol<smiles>Cc1ccc(O)c(O)c1</smiles>

4-Methycatechol

Figure 6. Four of the favored monomeric products of lignin: Phenol, Catechol, Guaiacol and 4-Methylcatechol.

Table 1. Monomer units of Indulin AT*.

\begin{tabular}{cc}
\hline \multicolumn{2}{c}{ Monomer basics } \\
\hline Sinapyl alcohol & $0 \%$ \\
p-Cumaryl alcohol & $2.5 \%$ \\
Coniferyl alcohol & $97.5 \%$ \\
\hline
\end{tabular}

${ }^{*}$ With J. Schäfer, Department of Food Chemistry and Phytochemistry, KIT.

rest is linked via $\beta-5$ and ends partly with cinnamyl alcohol groups (Figure 7).

\section{Experimental Procedure}

The aim of this work was to investigate the catechol yield at different temperatures $\left(250^{\circ} \mathrm{C}, 300^{\circ} \mathrm{C}, 350^{\circ} \mathrm{C}, 400^{\circ} \mathrm{C}\right.$ and $\left.450^{\circ} \mathrm{C}\right)$, the resulting pressures out of these temperatures and reaction times $(0.25-24 \mathrm{~h}$ ) utilizing a homogenous catalyst (1 wt\% potassium hydroxide $\mathrm{KOH})$. The screening experiments were performed in batch micro reactors (10 - $25 \mathrm{ml}$ ). Lignin and the potassium hydroxide solution are put in the stainless steel $(14,571)$ micro reactors under standard pressure. Figure 8 shows a scheme of the proceeding of the experiment.

The micro reactors $(10.0 \mathrm{ml}, 24.5 \mathrm{ml} \& 25 \mathrm{ml}$ volume) are filled with the lignin-base-suspension and sealed. The oven used for the heating, is a GC oven with a heating rate of $40^{\circ} \mathrm{C} / \mathrm{min}$. The reaction time starts after the target temperature is reached and an additional $15 \mathrm{~min}$ of heating have passed. After the reaction, the autoclaves are taken out of the oven and put under cold water to cool down and to stop the reaction.

Gas chromatography was mainly used for analyzing the gas and monomeric components in the product mixture. The gaseous samples are analyzed by an Agilent $7890 \mathrm{~A}$ GC-system with a $2 \mathrm{~m}$ Porapak Q column. An Agilent laboratory data system controls the measurement. For the detection of the compounds a flame ionization detector (FID) and a thermal conductivity detector (TCD) is applied. For the analysis of the liquid products a Hewlett Packard 5890-II GC system with a Hewlett Packard 5890 auto sampler equipped with a FID-detector. It is controlled by an HPChem laboratory data system. As column, a nonpolar 30 m RestekRtx 1 MS cross bond dimethylpolysiloxane column is used. 


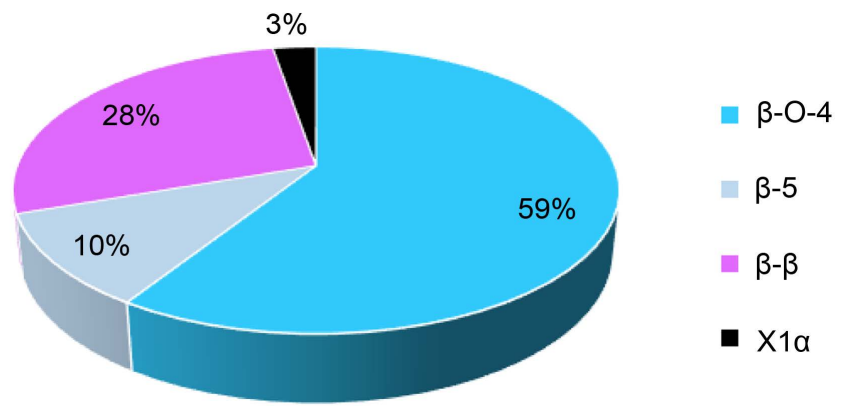

Figure 7. Different bond types of Indulin AT, (X1cinnamyl alcohol ending group) $)^{2}$.

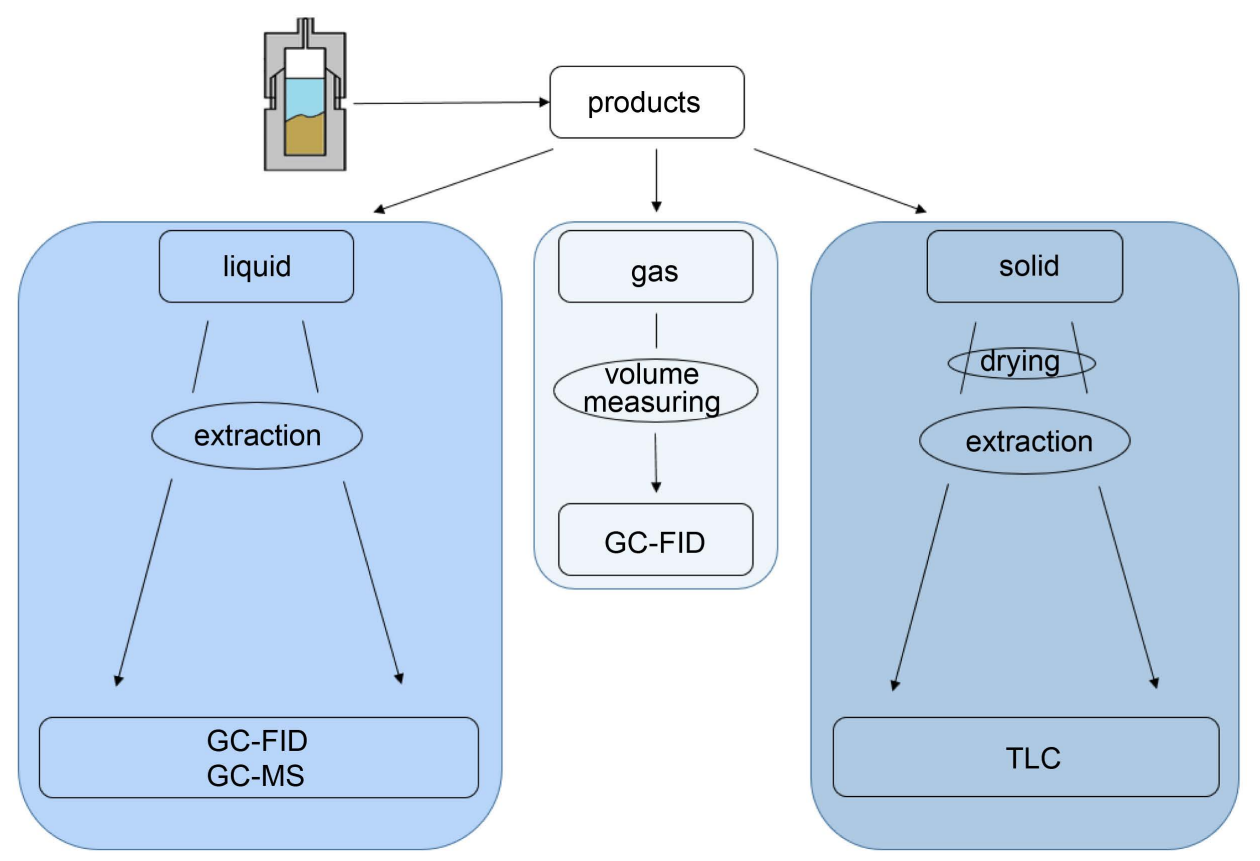

Figure 8. Proceeding of the experiments.

\subsection{Lignin Degradation}

Likewise said, in other studies the phenol yield was found to stagnate at a certain level and for the investigated Kraft lignin the phenol amount was found to be limited to a maximum yield below $10 \mathrm{wt} \%$ [6] [15].

Under the catalytical influence of Nickel, which was contained in the reactor material, the yield was found to be even lower. Figure 9 shows the phenol yields per g used lignin at $300^{\circ} \mathrm{C}$, at a $\mathrm{KOH}$ concentration of $1 \mathrm{wt} \%$ over different reaction times. After a certain time of $4 \mathrm{~h}$ the phenol yield remains at an amount below $3 \mathrm{wt} \%$. This observation can be explained with the catalytic activity of Nickel, which amplifies the gasification of biomass and is therefore often used as a catalyst for gasification reactions. However, with the gasification of biomass as a competing reaction, the amount of the targeted bifunctional products decreases rapidly.

Besides this, higher temperatures, a longer reaction time and a higher amount of the catalysts shift the reaction towards the gasification (compare Figure 10 and Figure 11).

${ }^{2}$ With J. Schäfer, Department of Food Chemistry and Phytochemistry, KIT. 
Over $350^{\circ} \mathrm{C}$ water is in near or supercritical conditions, which has special conditions and enhances the reaction in direction to gasification. At $250^{\circ} \mathrm{C}$ the cleavage reactions are slow, but also gasification reactions are much less occurring. Only after longer reaction times liquefaction occurs.

On contrary, at $450^{\circ} \mathrm{C}$ almost the complete reaction is turned towards gasification while the yield of the desired products is found to be nearly zero. To sum up, while below critical conditions $\left(250^{\circ} \mathrm{C}\right)$ the desired reactions are not happening, under supercritical conditions $\left(450^{\circ} \mathrm{C}\right)$ mostly gasification is occurring. However, this was expected, as other studies support these observations; compare Figure 1 [8] [9] [15].

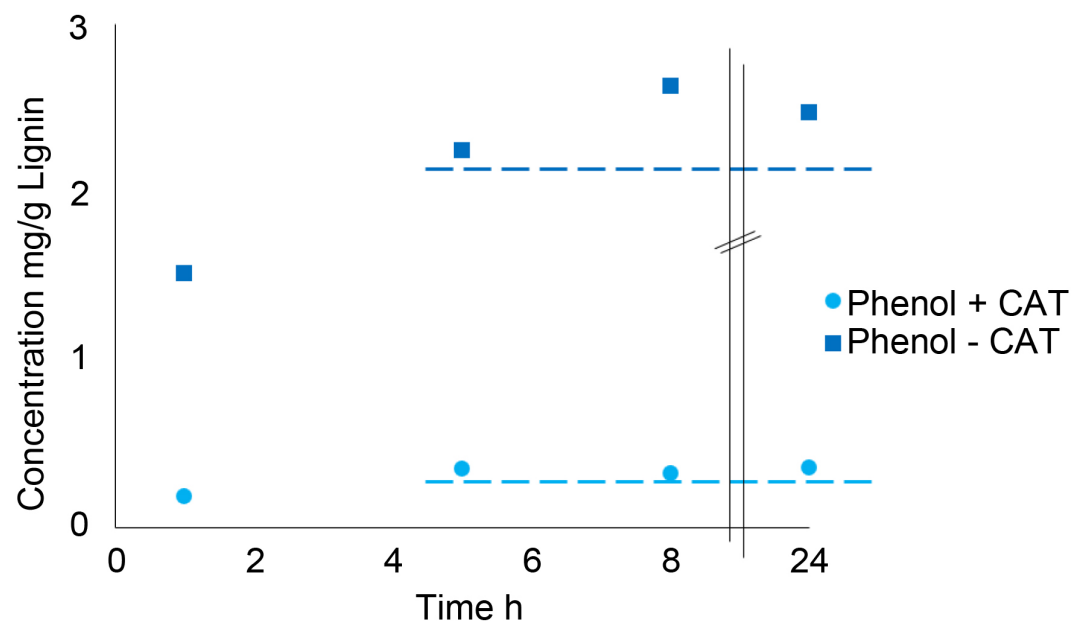

Figure 9. Phenol yields in mg per g used lignin at $300^{\circ} \mathrm{C}$ and the resulting pressure out of this temperature, a $\mathrm{KOH}$ concentration of $1 \mathrm{wt} \%$ was applied for different reaction times $(0.25-24 \mathrm{~h})$. The dark blue squares show the yield obtained without a Ni-catalyst, the light blue dots by addition a Ni-catalyst, resulting out of the reactor material.

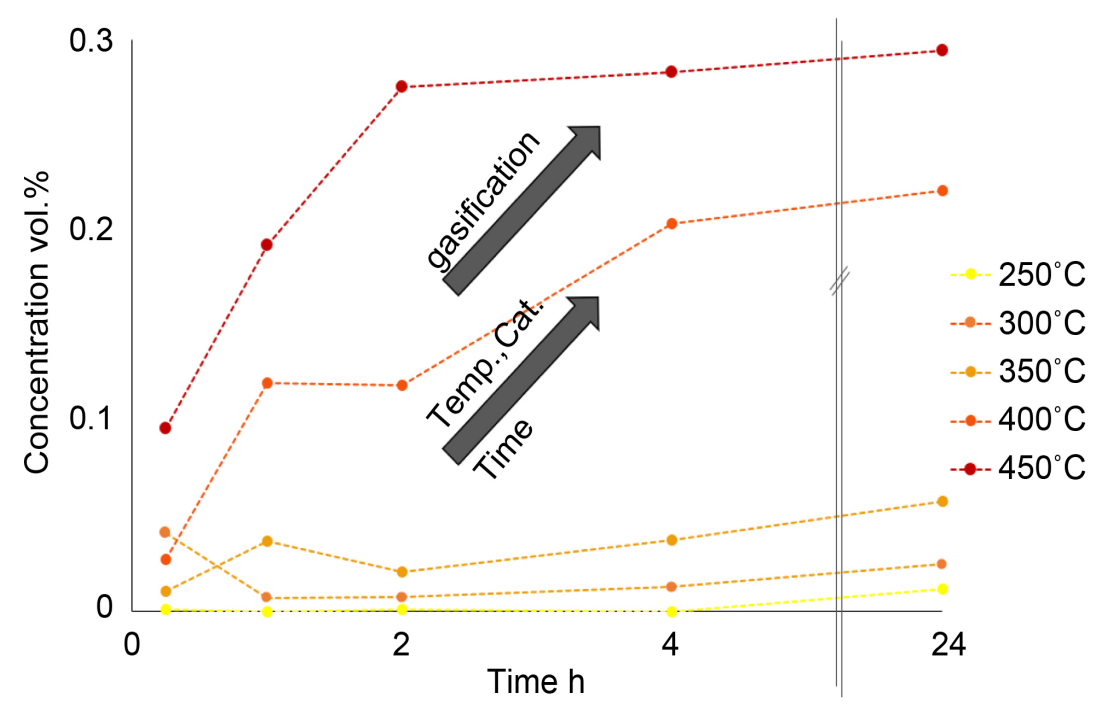

Figure 10. Concentrations of the obtained amount of methane in vol\% over the different reaction times $(0.25-24 \mathrm{~h})$ at different temperatures $\left(250^{\circ} \mathrm{C}-450^{\circ} \mathrm{C}\right)$, the resulting pressure out of these temperatures and a $\mathrm{KOH}$ concentration of $1 \mathrm{wt} \%$, biomass used for this was beech bark. 


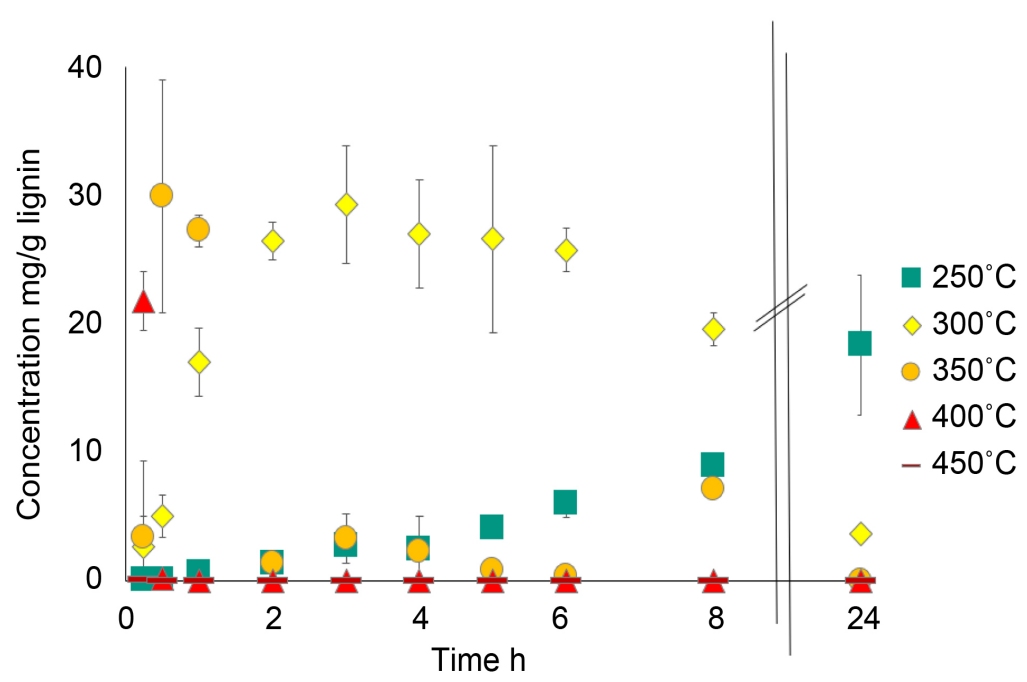

Figure 11. Concentrations of the obtained product catechol in mg per $\mathrm{g}$ used lignin over the different reaction times $(0.25-24 \mathrm{~h})$ and examined temperatures $\left(250^{\circ} \mathrm{C}-450^{\circ} \mathrm{C}\right)$, the resulting pressure out of these temperatures and $1 \mathrm{wt} \%$ $\mathrm{KOH}$.

Based on guaiacol as an intermediate, the favored product catechol is expected to be formed [15] [16] [17]. Figure 12 shows the concentration profile of guaiacol and catechol as a function of the reaction time at $300^{\circ} \mathrm{C}$ and a $\mathrm{KOH}$ concentration of $1 \mathrm{wt} \%$.

However, this is just one of the reaction pathways towards catechol (also described in [17]). In general, the highest amount of catechol could be achieved at $300^{\circ} \mathrm{C}$ and a reaction time of 3 hours.

\subsection{Reactivity of Indulin AT Compared to Beech Bark}

As described before, not only lignin can be applied in this process, also bark can be directly used. Bark also contains cellulose, hemicelluloses and extracts besides the lignin [5]. So, the reactions are expected to be influenced by the different molecular components present inside of the bark.

Currently, different studies are performed to investigate the influence of glucose on the reaction, as the cellulose is cleaved directly to glucose under the liquefaction conditions applied. Besides this a more detailed look on the influence of tannins present inside of the bark is intended.

Therefore, in this study, beech bark was used having a lignin content of $32 \mathrm{wt} \%^{3}$ based on own measurements and literature data [5]. Taking this into consideration, the observed catechol yield is comparable to the yield observed when using Indulin AT as a starting material, see Figure 13.

The yields of the other observed products, namely syringol and guaiacol, lead to the assumption that the basic monomers of the bark have to be in a different composition than the one present in Indulin AT, because there is more syringol observed in the product mixture of the bark experiments than compared to the experiments with Indulin AT (compare Figure 4) [5] [12] [13] [14].

${ }^{3}$ With M. Fleckenstein, University of Göttingen, Wood Biology \& Wood Products. 


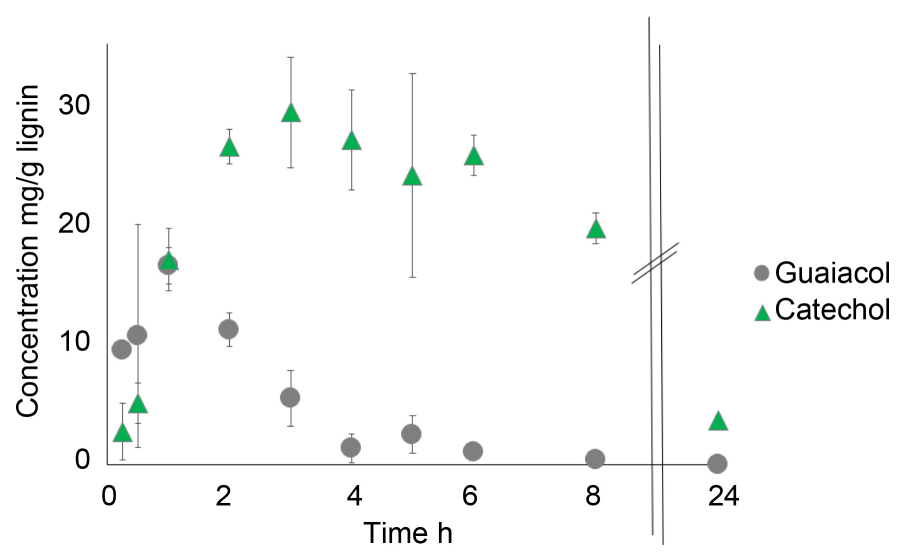

Figure 12. Concentrations of the obtained products guaiacol (grey dots) and catechol (green triangles) in mg per g used lignin over the different reaction times $(0.25-24 \mathrm{~h})$ at $300^{\circ} \mathrm{C}$, the resulting pressure out of this temperature and a $\mathrm{KOH}$ concentration of $1 \mathrm{wt} \%$.

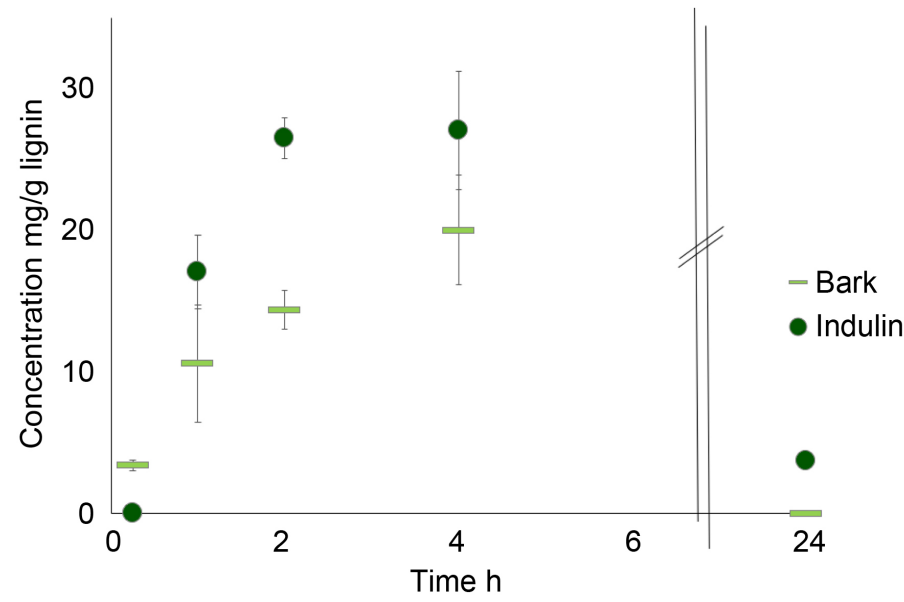

Figure 13. Concentrations of the obtained product catechol in mg per g used lignin (dark green dots) and lignin in the used bark (light green squares) over the different reaction times $(0.25-24 \mathrm{~h})$ at $300^{\circ} \mathrm{C}$, the resulting pressure out of this temperature and a $\mathrm{KOH}$ concentration of $1 \mathrm{wt} \%$.

\section{Outlook}

Previous work indicated an influence on the liquefaction reaction results, if there is back mixing in the reactor. In a continuous reactor with back mixing the products can interact with the unreacted feed and intermediately formed products [16] [18]. Repolymerization reactions may be hindered through the back mixing leading to a higher amount of bifunctional monomers. Furthermore, bifunctional oligomers may be available through a new process design which leads to the setup of a new reactor (Figure 14) set-up which is currently under construction.

Through the use of a loop reactor, the reactions shall be driven towards bifunctional components. These new influencing variables, the variable back mixing and number of cycles shall give a better control of the reactions. With this continuous system, the identification of important key components and their kinetics are possible. 


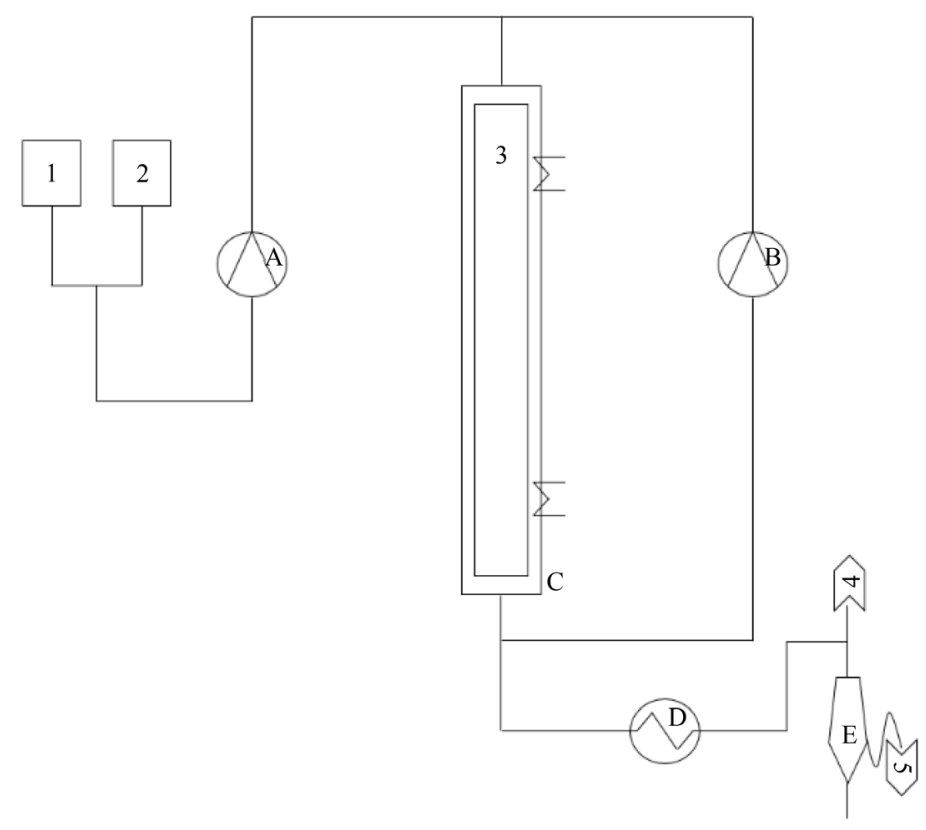

Figure 14. Scheme of the built loop reactor. 1 \& 2: Feed; 3: Reactor (1 1); 4: Gas products; 5: Liquid products; A \& B: Pumps; C: Heating system;

D: Heat exchanger; E: Phase separator.

\section{Conclusions}

Different lignin types need to be investigated separately, because they are found to generate a different product range. Furthermore, different types of biomass like bark need to be investigated more closely, because the different lignin composition leads to other reactions and thus, products.

The product spectra themselves are highly various, so the downstream processes need to be investigated in the future to build a sustainable process. A suitable separation technique must be found that the different platform chemicals can be gained out of the process in high qualities for further applications and conversions. Besides this, the mixture could be investigated in different areas where already phenolic mixtures are used. Until now, the down streaming has been hardly investigated; hence, the liquefaction process is not viable and ecological. Nevertheless, with the right down streaming processes and a suitable use of the products, it should be possible to develop an ecological and economical feasible process.

As a matter of fact, both feedstocks have a high potential as a source for platform chemicals. In regard to bio economy even more, as both are waste streams of the high volume pulping industry and which are used mostly not chemically by now. This work has a focus on the development of a whole new value chain, but the basic reactions need to be understood well before. Hydrothermal liquefaction appears as a reasonable conversion technology because functional groups remain in the product molecules. In particular, the oligomeric compounds which aren't investigated in detail until now are promising products for a chemical use. With different reaction times, temperatures and catalysts, the reaction towards bifunctional molecules can be influenced. This could lead to a higher earned value for the wood and paper sector. 


\section{Acknowledgements}

We acknowledge support by Deutsche Forschungsgemeinschaft and Open Access Publishing Fund of Karlsruhe Institute of Technology. This work by Julia Schuler was supported by a grant from the Ministry of Science, Research and the Arts of BadenWürttemberg. Az: 200007 as part of the BBW ForWerts Graduate Program. B. Rolli, S. Habicht, H. Köhler and A. Lautenbach are acknowledged for the analyses of the organic and aqueous products. J. Schäfer, Department of Food Chemistry and Phytochemistry KIT, is acknowledged for the analysis of the lignin structure. Thanks go to M. Fleckenstein, University of Göttingen, Wood Biology \& Wood Products, for the combined measurements of the bark.

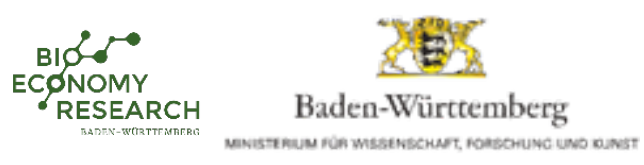

\section{References}

[1] Sitte, P., Weiler, E., Kadereit, K., Bresinsky, A. and Körner, C. (2002) Lehrbuch der Botanik für Hochschulen, 35. Auflage, Spektrum Akademischer Verlag, Heidelberg.

[2] Lüttge, U., Kluge, M. and Bauer, G. (1994) Botanik, 2. Auflage, VCH, Weinheim.

[3] Puls, J. (2009) Lignin-Verfügbarkeit, Markt und Verwendung: Perspektiven für schwefelfreie Lignine. Gülzower Fachgespräche, 31, 18-41.

[4] Glasser, W. (2009) Lignin-Retrospect and Prospect. Gülzower Fachgespräche, 31, 42-44.

[5] Feng, S., et al. (2013) Valorization of Bark for Chemicals and Materials: A Review. Renewable and Sustainable Energy Reviews, 26, 560-578. https://doi.org/10.1016/j.rser.2013.06.024

[6] Forchheim, D., Hornung, U., Kruse, A. and Sutter, T. (2014) Kinetic Modelling of Hydrothermal Lignin Depolymerisation. Waste and Biomass Valorization, 5, 985-994. https://doi.org/10.1007/s12649-014-9307-6

[7] Dorrestijn, E., Kranenburg, M., Poinsot, D. and Mulder, P. (1999) Lignin Depolymerization in Hydrogen-Donor Solvents. Holzforschung, 53, 611-616. https://doi.org/10.1515/HF.1999.101

[8] Kruse, A. and Dahmen, N. (2015) Water-A Magic Solvent for Biomass Conversion. The Journal of Supercritical Fluids, 96, 36-45. https://doi.org/10.1016/j.supflu.2014.09.038

[9] Wang, X. and Rinaldi, R. (2012) Solvent Effects on the Hydrogenolysis of Diphenyl Ether with Raney Nickel and Their Implications for the Conversion of Lignin. ChemSusChem, 5, 1455-1466. https://doi.org/10.1002/cssc.201200040

[10] Personal Communication with Member of University of Göttingen, Wood Biology \& Wood Products.

[11] Donaldson, L. (2013) Softwood and Hardwood Lignin Fluorescence Spectra of Wood Cell Walls in Different Mounting Media. IAWA Journal, 34, 3-19. https://doi.org/10.1163/22941932-00000002

[12] Bunzel, M. and Ralph, J. (2006) NMR Characterization of Lignins Isolated from Fruit and Vegetable Insoluble Dietary Fiber. Journal of Agricultural and Food Chemistry, 54, 83528361. https://doi.org/10.1021/jf061525z

[13] Faravelli, T., Frassoldati, A., Migliavacca, G. and Ranzi, E. (2010) Detailed Kinetic Modeling of the Thermal Degradation of Lignins. Biomass and Bioenergy, 34, 290-301. https://doi.org/10.1016/j.biombioe.2009.10.018

[14] Jegers, H.E. and Klein, M.T. (1985) Primary and Secondary Lignin Pyrolysis Reaction Path- 
ways. Industrial and Engineering Chemistry Process Design and Development, 24, 173-183. https://doi.org/10.1021/i200028a030

[15] Wahyudiono, Sasaki, M. and Goto, M. (2008) Recovery of Phenolic Compounds through the Decomposition of Lignin in Near and Supercritical Water. Chemical Engineering and Processing: Process Intensification, 47, 1609-1619. https://doi.org/10.1016/j.cep.2007.09.001

[16] Forchheim, D. (2013) Optimization of the Reaction Parameters of a CSTR and a PFR (Batch) for the Recovery of Phenol from Hydrothermal Biomass Liquefaction.

[17] Tekin, K., Karagöz, S. and Bektaş, S. (2014) A Review of Hydrothermal Biomass Processing. Renewable and Sustainable Energy Reviews, 40, 673-687.

https://doi.org/10.1016/j.rser.2014.07.216

[18] Wahyudiono, Sasaki, M. and Goto, M. (2011) Thermal Decomposition of Guaiacol in Suband Supercritical Water and Its Kinetic Analysis. Journal of Material Cycles and Waste Management, 13, 68-79. https://doi.org/10.1007/s10163-010-0309-6

\section{Submit or recommend next manuscript to SCIRP and we will provide best service for you:}

Accepting pre-submission inquiries through Email, Facebook, LinkedIn, Twitter, etc. A wide selection of journals (inclusive of 9 subjects, more than 200 journals)

Providing 24-hour high-quality service

User-friendly online submission system

Fair and swift peer-review system

Efficient typesetting and proofreading procedure

Display of the result of downloads and visits, as well as the number of cited articles

Maximum dissemination of your research work

Submit your manuscript at: http://papersubmission.scirp.org/

Or contact jbnb@scirp.org 